\title{
Consolidating Research on Population Dynamics and Health of the Urban Poor in Sub-Saharan Africa: An Overview
}

\author{
Blessing Mberu', Caroline W. Kabiru ${ }^{2}$, Donatien Beguy ${ }^{3}$ and Alex C. Ezeh ${ }^{4}$ \\ African Population and Health Research Center, Nairobi, Kenya \\ bmberu@aphrc.org
}

\begin{abstract}
Though the least urbanized globally, sub-Saharan Africa (SSA) is rapidly urbanizing, with its urban population projected to reach $55 \%$ by 2050 . While cities continue to offer greater amenities, better employment opportunities and better services, they also concentrate risks and hazards for health, which is exacerbated by majority of urban dwellers living in slums or slum-like conditions that are detrimental to their living and health conditions. Understanding specific health and livelihood conditions of slum dwellers require adequate data at local levels often lacking through national surveys, which mostly provide national indicators, and blur inter- and intra-sub-group inequities. The papers in this series use unique datasets mostly aggregated at local levels to portray the specific living and health conditions in slum areas. They collectively contribute rich evidence for policy and action in the important search for pathways to reduce health inequities and improve living conditions among the urban poor in Kenya and across SSA.
\end{abstract}

\section{Résumé}

Bien que le moins urbanisé au niveau mondial, l'Afrique subsaharienne (ASS) est d'urbanisation rapide, avec sa population urbaine devrait atteindre $55 \%$ en 2050 . Alors que les villes continuent à offrir de meilleures commodités, de meilleures possibilités d'emploi et de meilleurs services, ils se concentrent aussi les risques et les dangers pour la santé, qui est exacerbé par la majorité des citadins vivant dans des taudis ou des bidonvilles comme qui sont préjudiciables à leurs conditions de vie et de santé. Comprendre les conditions spécifiques de santé et de subsistance des habitants des bidonvilles ont besoin de données adéquates au niveau local manquent souvent par le biais d'enquêtes nationales, qui fournissent la plupart des indicateurs nationaux, qui brouillent les inégalités inter et intra-sous-groupe. Les documents de cette série utilisent des ensembles de données uniques principalement agrégées au niveau local pour décrire les conditions de vie spécifiques dans les bidonvilles. Ils contribuent collectivement preuve riche de la politique et de l'action dans la recherche importante pour les voies pour réduire les inégalités de santé et améliorer les conditions de vie des pauvres en milieu urbain au Kenya et à travers l'Afrique subsaharienne.

\section{Background and Introduction}

Since 2007, more than $50 \%$ of the world's population live in urban areas. While sub-Saharan Africa (SSA) remains predominantly rural, the share of its urban population is projected to increase from $37 \%$ in 2014 to $55 \%$ by 2050 (UNDESA, 20I4). People are attracted to cities because they generally offer more choices (such as good quality housing), opportunities (such as employment) and services (such as education and health care). However, cities also concentrate risks and the impact of adverse events such as water contamination, air or noise pollution and natural disasters are amplified in densely populated urban settings (WHO \& UNHABITAT, 20I0). Further, a mismatch between rapid population growth of cities and the ability of governments to provide infrastructure and opportunities essential for leading fulfilling lives compounds these risks (WHO \& UN-HABITAT, 2010). Among global city dwellers today, almost 900 million people live in areas considered slums and in 2013 , about $62 \%$ of the urban population in SSA lived in slums or slum-like conditions (UN-HABITAT, 20I0, 2013; UNDESA, 20I2). Slums are characterized by overcrowding, social and economic marginalization, poor environmental conditions, insecurity and the near absence of basic social services (UN-HABITAT, 2006; 2003; World Bank, 200I). Consequently, the commonly assumed urban advantage has been challenged in many low and middle income countries, raising intricate social policy challenges around resilience and viability of life in cities in many countries (APHRC, 2014, Fotso et al., 2009). 
Nairobi, Kenya's capital city, is a typical example of an African city that is growing at a rapid rate, despite poor urban governance, limited employment and a dearth of other life-enhancing opportunities for existing and incoming dwellers. Between 1969 and 1999 the city grew at a rate of about $5 \%$ per annum (Agwanda and Bocquier, 2004) and by the 2009, when the most recent census was conducted, Nairobi had a population of 3 million. Despite being an established business and cultural hub, the city was home to some of the most dense, unsanitary and insecure slums, with over 100 slums and squatter settlements within the city (UN-HABITAT, 2003). Studies have brought to focus the excess mortality and disease burden among the city's slum dwellers compared to any other subgroup in the country (Madise et al., 20I2, APHRC, 20I4, APHRC, 2002).

The grim situations associated with urban slum living have attracted global attention and led to a call for concerted efforts and actions to address the economic and health challenges of slum dwellers (or the urban poor), prominent among which is the adoption in 2000 of the Millennium Development Goal (MDG) 7, Target II that aims to improve the lives of at least 100 million slum dwellers by 2020 (UN-HABITAT 2003). Following the global push for the achievement of the MDGs and enhanced accountability on the part of the Government of Kenya (GoK), substantial attention and resources were invested by the Government, development partners, and non-governmental organizations to improve health and economic outcomes in the country. For instance, the Nairobi Cross-sectional slum Survey report (APHRC, 20I4) identified several investments that are targeted at improving the life of the urban poor in the last decade. Such interventions include the Ministry of Health in Kenya, which introduced a budget line for contraceptive commodities and made a policy shift on health service access whereby children under 5 years of age received free treatment at public health facilities (2002). Further, there were several slum-specific projects such as slum upgrading (initiated in 200I), cash transfers to older persons (pilot launch in 2006; official launch, 2009), Output Based Approach Voucher scheme to enable poor women deliver in hospitals (2005), policies to provide non-formal schools in slums with government support under the free primary education program (2010), and allocation of funding for hand-washing in schools to improve health outcomes. Other notable interventions in the past decade include the World Bank Water and Sanitation Programme-Africa (WSPA) in Kenya, the Pamoja Trust and the National Cooperative Housing Union (NACHU), both of which are active in housing for the urban poor, and activities around HIV/AIDS treatment and prevention by such agencies as the National AIDS Control Council, UNAIDS and UNICEF.

Results from the Kenya Demographic and Health Survey (KDHS) in 2008-09 show general improvements in key social, economic and health indicators at the national level (KNBS \& ICF Macro 20I0). However, due to the limited coverage of slum residents in national sample surveys, the reports are unable to answer a number of questions that are specifically critical to the health and livelihood of the urban poor, who constitute the majority of city dwellers (APHRC 20I4). Further, national indicators generally blur inter- and intra-sub-group inequities and often lack aggregation at local levels. Yet, taking stock of whether the urban poor have also benefited from the improvements observed at national level require adequate data at local levels. This disaggregation will help implementing agencies and local governments pinpoint priorities, measure progress, and identify interventions that work or otherwise (Satterthwaite, 20I4).

As part of the search for pathways to reduce health inequities and improve living conditions among urban poor in Kenya and in other parts of subSaharan Africa, the African Population and Health Research Center developed two main data collection initiatives to fill the gap in getting specific, reliable, accurate and timely data that portray the unique living conditions of urban slum dwellers in Kenya. These include the Nairobi Cross-sectional Slums Survey (NCSS), a unique DHS-type survey among representative samples of the slum population in Nairobi city conducted in 2000 and 2012, and the Nairobi Urban Health and Demographic Surveillance System (NUHDSS), a pioneering urban-based longitudinal platform implemented in two of the Nairobi city's numerous slum settlements since 2002.

\section{About this volume}

The papers in this series, which draw on data from the 2000 and 2012 NCSSs, the NUHDSS and other data sources, are designed to consolidate research on the urban poor as well as fill critical knowledge gaps by documenting their demographic and health challenges. They contribute to the critical search for pathways to reduce health inequities and improve health outcomes, including sexual and reproductive health among populations in resource-poor urban settings in Kenya and other parts of SSA. The ultimate goal is to provide the evidence base to guide policies and programs aimed at improving the health and wellbeing of the urban poor.

In the first paper titled Effect of Changing Proximate Determinants on Fertility Levels among Urban Poor Women in Kenya: Evidence from 
Nairobi's Informal Settlements, 2000-20/2, Wamukoya and colleagues examine changes in the proximate determinants of fertility in slums in Nairobi, Kenya between 2000 and 2012 using data collected from over 7,000 women of reproductive age. This paper contributes to filling the evidence gap about fertility patterns and determinants among the urban poor in sub-Saharan Africa They employed Stover's revised proximate determinants of fertility framework to assess the relative contribution of contraception, marriage, sterility and postpartum insusceptibility to the fertility levels between 2000 and 20I2. They found a change in the influence of the proximate determinants of fertility in Nairobi's slums over the study period. Exposure to pregnancy as measured by recent sexual activity had the largest inhibiting effect followed closely by contraception in 2000, whereas in 2012 contraception had the largest fertility inhibiting effect followed by marriage. The contraception inhibiting effect was much larger than that of marriage effect in 20/2. The findings of the paper underscore the need to sustain and/or strengthen sexual and reproductive health initiatives that emphasize contraceptive use among women in urban slums in Kenya as a key factor in achieving fertility decline in the country.

The second paper by Mberu and colleagues on Fertility and Household Economic Outcomes among Poor Urban Households in Nairobi informal Settlements uses data on 6,324 households from the NUHDSS to investigate the effects of additional children on household poverty transitions between 2006 and 2009. Over the four years of observation, more households fell into rather than moved out of poverty, while more households remained in chronic poverty than those who stayed out of poverty over the study period. Having a birth in a household was found to be a significant net predictor of a household falling into poverty and lessened the household's prospects of moving out of poverty over the observation period. Following the inevitable expenditures associated with infants' total care, the findings of the paper provide compelling quantitative support for poverty alleviation interventions that include the promotion of voluntary contraceptive programs and smaller family size norms as part of the strategies to address persistent poverty among the urban poor.

Building on the linkages between high levels of migration, rapid urban growth and health outcomes, Mutombo and colleagues present in the third paper a regional synthesis of evidence from literature on the health vulnerabilities among migrant/mobile populations in urban settings of East and Southern Africa. Using the principles of reputational case selection sampling procedures and thematic search of electronic databases and websites, the team implemented a regional synthesis of evidence on the health vulnerabilities of migrant and mobile populations in urban areas of East and Southern Africa. The review identified key health challenges relating to various diseases. For example, the challenge of diabetes is projected to increase significantly by 2030 . The review suggested high levels of urban refugees, internally displaced persons and asylum seekers in urban areas of the region, which poses particular logistics challenges in terms of administering targeted interventions, more so in contexts where poor socio-economic situations of host countries do not provide them opportunities to become self-reliant and less dependent on humanitarian assistance. The authors call for policies and program interventions and research investments targeting vulnerable migrant and mobile groups in the region.

Specifically focusing on two of Nairobi slums, Faye and colleagues identified the correlates of and spatial differences in under-five mortality in urban informal settlements. Looking beyond individual level factors that are often associated with under-five mortality such as socio-economic status, nutritional status, and poor access to health services, they examined geographical predictors of child mortality in two Nairobi slums of Korogocho and Viwandani using a Bayesian geo-additive survival model, accounting for spatial random effects. The study used longitudinal data of 30,339 children aged below 5 years for the period 2006-20 I I from the NUHDSS. In addition to determinants such as mother's education and age, size of the household and ethnicity, the study finds a spatial structure in child mortality risk, with differences strongly evidenced between some villages in Viwandani while no spatial variations were observed in Korogocho. The results reinforce the heterogeneity of slums within one city and call for specific efforts from policymakers to refine child health interventions in urban slums by incorporating the concept of space and spatial differences within informal settlements.

Addressing maternal mortality, which remains a key health challenge among the urban poor, Obare and colleagues examined factors contributing to maternal mortality in relatively resource-endowed urban contexts of developing countries, with specific focus on Nairobi, Kenya. The study uses data from 93 records of maternal deaths at health facilities, as well as verbal and social autopsy interviews with 7l caregivers of women who died of maternal-related causes in the study community. Results show that most maternal deaths occurred to women who were young, married, with low levels of education and those having at least two births. In addition, maternal 
deaths in the city were mostly due to poor healthseeking behaviour, delays at the household level in seeking care, poor referral mechanisms between facilities, poor provider attitudes, and lack of skilled human resources. The findings suggest that empowering households to recognize danger signs early, improving referral mechanisms, and enhancing the capacity of providers to offer quality services can contribute to improved maternal health indicators.

A pathway to reducing maternal mortality and advancing maternal health is improving timely and adequate antenatal care (ANC) attendance. In their paper, Muindi and colleagues assessed the determinants of timing and frequency of antenatal care utilization in Nairobi slums in 2000 and 2012. Using data from 2000 and 2012 NCSSs and fitting multinomial logistic regression models, the paper assessed factors associated with timing of the first ANC visit and the frequency of ANC visits. In both years, though a decade apart, parity, mother's ethnic group and educational attainment were significantly associated with timing of first ANC visit. Frequency of visits was significantly associated with mother's educational attainment, parity, pregnancy wantedness and place of residence. For optimal ANC utilization, the authors underscore the need to improve women's educational outcomes and addressing of cultural barriers to ANC utilization.

Contributing to the growing evidence of epidemiological transition in SSA, with increasing incidence of non-communicable diseases (NCDs) as a public health issue, Haregu and colleagues in their paper examined the association between NCD risk factors and risk perception among urban slum dwellers in Nairobi, Kenya. The paper builds on the rising contribution of NCDs as a cause of death among the urban poor. The analysis is based on data from 5,190 study participants collected between 2008 and 2009 as part of a cross-sectional survey that was designed to assess linkages between socioeconomic status, perceived personal risk, and risk factors for cardiovascular and non-communicable diseases in urban slums of Nairobi. In sum, the authors found a low risk perception about NCDs in spite of the presence of NCD risk factors. Their findings suggest the need for programmes aimed at creating awareness about NCDs and promoting the adoption of preventive healthy lifestyles among the poor urban populations.

In a search for preventive health care service delivery models that work for the urban poor, Mberu and colleagues in their paper, Reaching the Urban Poor with Health Interventions: The Case of HIV Testing in Nairobi Urban Informal Settlements, examined the levels, modes and correlates of HIV testing among residents of Nairobi informal settlements. The paper builds on the premise that HIV testing and counseling (HCT) is an entry point to HIV prevention, treatment, and care in Kenya. The paper sought to establish whether the urban poor, who are often not adequately covered in national level statistics, have benefited as much as other groups from the progress registered in HIV testing at the national level and to identify the success factors. Drawing on data from 6,035 women and men of reproductive age interviewed in the 2012 NCSS and II,909 women and men interviewed in the 2008/09 Kenya Demographic and Health Survey, the study found that a greater proportion of Nairobi slum dwellers had been tested for HIV compared with residents in other parts of Nairobi and Kenya as a whole. They argue that this counter-intuitive finding is partly explained by results showing the specific advantage of slum dwellers over the rest of the country in accessing HIV testing services through mobile clinics and research studies. Sub-groups with established disadvantage in accessing health services through public institutions, such as women aged I519 years and the never married were most likely to be tested in mobile clinics or research studies. In the search for what works for disadvantaged groups and hard to reach populations, the findings of the study underscore the importance of targeted and customized interventions to reduce inequities in access to health services in general and HTC services in particular.

In another paper examining service delivery models, Bakibinga and her colleagues examined the use of private and public health facilities for essential maternal and child health services in Nairobi's informal settlements, drawing on perspectives of women and community health volunteers ( $\mathrm{CHVs}$ ). The paper described the sources of care for delivery, family planning and child welfare services in Nairobi's slums and further explored the perceptions of women and community health volunteers regarding choice and quality of services at health facilities. Data are drawn from a cross-sectional study conducted in 2013 involving interviews with 849 women aged I249 years, 968 caregivers of children under five years, and focus group discussions with a subset of the women and community health volunteers. The findings showed that most women sought delivery care and family planning services from private health facilities. Private health facilities were preferred because of ease of access and quality of care although their service fees were considered high. By contrast, public health facilities were viewed as affordable and staffed by qualified personnel although they were characterized by long queues and poor provider attitudes. Consequent upon the merits and demerits of the two sectors and their respective roles in health 
care provision in urban poor settings, the authors underscored the need to support better publicprivate relationships in which the positive aspects of each sector are utilized to improve health service delivery among the urban poor.

In the final paper also targeting service delivery models for the urban poor, Osindo and colleagues examined the challenges and opportunities for promoting maternal, new born, and child health in Nairobi urban informal settlements, building on the perspectives of community health volunteers ( $\mathrm{CHVs}$ ). Informed by evidence that $\mathrm{CHVs}$ are recognised as first line health care providers, globally and in Kenya, the paper uses data from four group discussions with $\mathrm{CHVs}$ and two key informant interviews with subCounty Community Strategy Coordinators to examine the lived experiences of $\mathrm{CHVs}$. The findings show that meaningful engagement of $\mathrm{CHVs}$ is hampered by lack of logistical support, recognition, insecurity, and inadequate resources. Despite the bottlenecks, voluntarism is their greatest driving force. The authors noted that the work of CHVs could be enhanced through logistical support from the government as it relates to training, provision of equipment, remuneration and recognition in the community and suggested that there is need for close coordination between the national government and the community units for $\mathrm{CHVs}$ to contribute to improved health outcomes at the local level.

\section{Conclusion}

The projected growth in the absolute number of slum dwellers demands sustained investments in improving the lives of urban dwellers, particularly the most vulnerable. In the context of the SDGs, especially Goal II, Target II.I that calls for making cities more inclusive by ensuring access for all to adequate, safe and affordable housing and basic services and upgrade slums by 2030 , the papers in this volume are critical guide posts on key population profiles and health challenges of the urban poor. The papers also provide insights into the predictors of their health service utilization and potential avenues to reach the most vulnerable populations in urban areas with critical health and social services. Building on the need for local governments to pinpoint priorities, measure progress, and identify interventions that work or otherwise, the findings in this volume provide important pointers on the nature of policies that governments and development partners can explore to uplift the health status of the urban poor, whose health, economic and social status will increasingly shape national indicators on health, poverty, and other development issues (Zulu et al., $20 \mathrm{II}$ ). Finally, the studies presented in this volume underscore the importance of slum specific investment in data collection efforts for sustained examination of issues, perspectives and service delivery models relevant for understanding the urban poor and to inform future policy and action.

\section{References}

AFRICAN POPULATION AND HEALTH RESEARCH CENTER (APHRC) 2002. Population and health dynamics in Nairobi's informal settlements: Report of the Nairobi Crosssectional Slums Survey (NCSS) 2000, Nairobi, APHRC.

AFRICAN POPULATION AND HEALTH RESEARCH CENTER (APHRC) 20I4. Population and Health Dynamics in Nairobi's Informal Settlements: Report of the Second Nairobi Cross-sectional Slums Survey (NCSS) 2012, Nairobi, APHRC.

AGWANDA, A. O. \& BOCQUIER, P. 2004. An event history analysis of factors influencing entry into parenthood in Nairobi. African Population Studies, 19, 43-62.

FOTSO, J., EZEH, A., MADISE, N., ZIRABA, A. \& OGOLLAH, R. 2009. What does access to maternal care mean among the urban poor? Factors associated with use of appropriate maternal health services in the slum settlements of Nairobi, Kenya. Maternal and Child Health Journal, I3, I30-137.

KENYA NATIONAL BUREAU OF STATISTICS (KNBS) \& ICF MACRO 20I0. Kenya Demographic and Health Survey 2008-09, Calverton, Maryland, KNBS and ICF Macro.

MADISE, J. N., ZIRABA, A. K., INUNGU, J., KHAMADI, S. A., EZEH, A., ZULU, E. M., KEBASO, J., OKOTH, V. \& MWAU, M. 20I2. Are slum dwellers at heightened risk of HIV infection than other urban residents? Evidence from population-based HIV prevalence surveys in Kenya. Health \& Place, I8, I I 44-I I 52.

SATTERTHWAITE D. (20/4). Health in urban slums depends on better local data. Manchester, United

Kingdom: I Ith International Conference on Urban Health; 2014.

UNDESA (UNITED NATIONS DEPARTMENT OF ECONOMIC AND SOCIAL

AFFAIRS/POPULATION DIVISION). 20I2. World urbanization prospects: The 20I I revision.

New York: United Nations.

UN-HABITAT. 20I3. State of the world's cities 20I2/20I3. New York, USA: Routledge; 2013. . 2010. The State of African Cities

2010: Governance, Inequality and Urban Land Markets. Nairobi, United Nations. 
UN-HABITAT. 2006. The State of the World's Cities Report 2006/2007: 30 Years of Shaping the Habitat Agenda. Nairobi, Kenya: UN-HABITAT.

UN-HABITAT (2003). The Challenge of Slums: Global Report on Human Settlements. Nairobi: UN-HABITAT.

UN-HABITAT. (200I). Cities in a Globalizing World: Global Report on Human Settlements. London: Earthscan Publications

WORLD HEALTH ORGANIZATION [WHO] \& UNITED NATIONS HUMAN SETTLEMENTS PROGRAMME (UN-HABITAT) 20I0. Hidden Cities: Unmasking and Overcoming Health Inequities in Urban Settings, Kobe, Japan, WHO Center for Health Development and UNHABITAT.

ZULU, E., BEGUY, D., EZEH, A., BOCQUIER, P., MADISE, N., CLELAND, J. \& FALKINGHAM, J. 20I I. Overview of migration, poverty and health dynamics in Nairobi city's slum settlements. Journal of Urban Health, 88, I85-199. 